\title{
Analysis of Mechanical Properties SMAW Welding Joints of Portable Electric Hydraulic Jack Frame
}

\author{
Andika Wisnujati ${ }^{1, a}$ and Juni Andryansyah ${ }^{1, b}$ \\ ${ }^{1}$ Program Studi D3 Teknologi Mesin, Program Vokasi Universitas Muhammadiyah Yogyakarta \\ Jl. Lingkar Selatan, Tamantirto, Kasihan, Bantul, DIY \\ aandikawisnujati@umy.ac.id, buniandryansyah05@gmail.com
}

\begin{abstract}
Abstrak--Welding is a very important part of the development and growth of the industry because it has a role in engineering, reparation, and construction. Shielded Metal Arc Welding (SMAW) or the conventional arc welding process is particularly dominant in structural joints, pressure vessels and in maintenance and repair work. In welding, different metals are joined economically and at a much faster rate as compared with other fabrication processes like riveting and casting. The purpose of this research is to find out the cooling media cooler against SMAW smelter tensile strength by using the E6013 electrode. This study uses low carbon steel material that has levels $\mathrm{Fe}=98,3 \% ; \mathrm{C}=0,30 \%, \mathrm{Si}=0,23 \%$. The material is given $75 \mathrm{~A}$ welding current with cooling variation on the connection result using oil, water, and room temperature. The highest tensile stress value obtained in the oil cooling treatment was $844,76 \mathrm{~N} / \mathrm{mm}^{2}$, the highest strain value was obtained on the raw materials of $16 \%$, the highest elasticity value was obtained in the oil cooling treatment of $703.96 \mathrm{~N} / \mathrm{mm}^{2}$. According to the research results can be concluded that the variations of cooling media greatly affect the strength of the welding connection.
\end{abstract} steel

Keywords: Mechanical properties, welding SMAW, low carbon

\section{Introduction}

Shielded Metal Arc Welding (SMAW) or the conventional arc welding process is particularly dominant in structural joints, pressure vessels and in maintenance and repair work. This method is commonly used in many manufacturing applications due to its flexibility, usability and indoor and outdoor use [1]. Factors that can affect welding is the welding procedure is one of the plans to conduct research that includes how to make welding construction under the plan and specifications by determining all things that will be needed in the implementation. One of the considerations involved in the development of welding is the time of manufacture, the equipment and supplies to be used, the fabrication process, the order of implementation, the planning of welding (including the selection of welding devices, the specification of welding lines to be used, the assignment of welders, the type of pattern used) [2].

When welding objects that are of greater importance, welding metal with steel wire is attached to a single device. It ensures that the strength of the welding wire will be the same as the actual wire used. Commonly, the reliability of the weld will not suit the target as it is vulnerable to welding defects created [3]. The welding process is used in all small and large workshops where it is often used to rebuild the damaged components. A large portion of the manufacturing field is focused on activities relating to the implementation of various joining techniques. Welding has the bonus that it has already been studied in vacuum. It is a production method that has direct implementation in air, water and space. Welding is used in various industrial industries such as automobile, aerospace, shipbuilding, mining, nuclear, power generation, telecommunications, household appliances, hydrocarbons and computer manufacturing, etc [4]. In welding, dissimilar metals are applied to join economically though at a greater rate compared to other manufacturing processes such as enthralling and casting. [5].

Tensile Strength of Welding Results SMAW ST 37 Steel Plate With Liquid Cooler has the highest voltage value of $144.27 \mathrm{kgf} / \mathrm{mm}^{2}$ an increase of $5.64 \mathrm{kgf} / \mathrm{mm}^{2}$ from the oil cooling treatment for 5 seconds which is $138.63 \mathrm{kgf} / \mathrm{mm}^{2}$ [6]. Research with SAE 10W-40 Oil cooling media has an average value of $144.27 \mathrm{kgf} / \mathrm{mm}^{2}$ and $5.19 \%$ strain and then with radiator coolant (RC) cooling media has a voltage of $142.03 \mathrm{kgf} / \mathrm{mm}^{2}$ and strain is $3.65 \%$ [7].

This study aims to determine the effect of the cooling media on the tensile strength of low carbon steel carried out by the SMAW welding process. In addition, to find out the correct cooling variable so that the welding results are strong and to know the strength of the SMAW welding results by applying some cooling 
variations oil, water and room temperature through tensile testing on low carbon steel in the making of portable electric hydraulic jack frame.

\section{Research Methodology}

\section{A. Tools and Materials}

The tools used in this study were SMAW welding machines, grinding machines, material composition testing and tensile testing machine. The materials used in this study were E6013 electrodes and low carbon steel using electric current 75 ampere. The process about SMAW welding shown in figure 1 below.

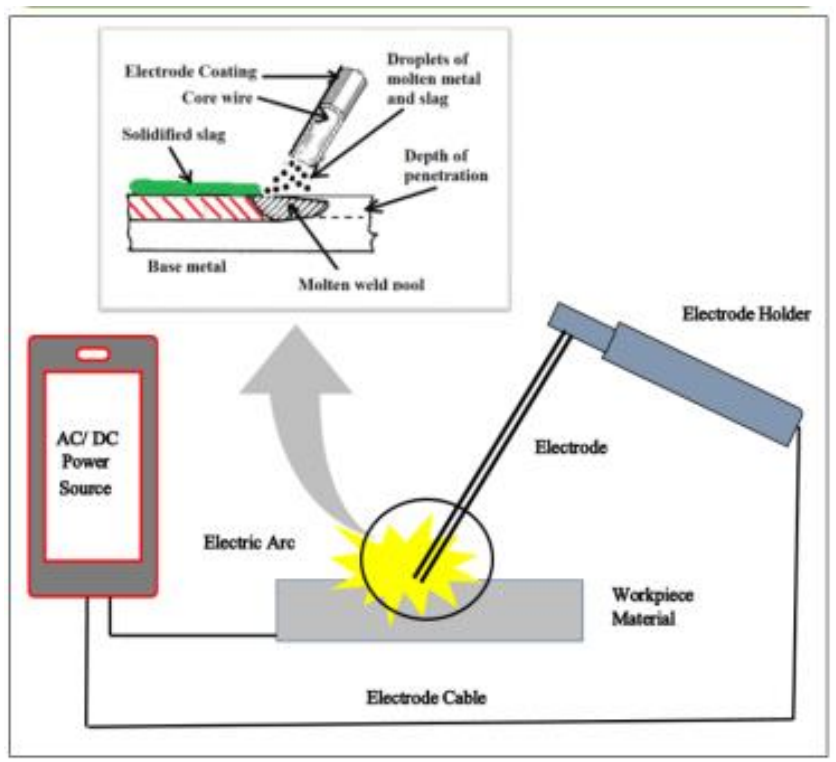

Figure 1. SMAW Process [4]

The location of the activity is carried out in the Diploma Laboratory of Mechanical Technology Universitas Muhammadiyah Yogyakarta, located at Jl. H.O.S. Cokroaminoto, Pakuncen, Wirobrajan, Yogyakarta City, Special Region of Yogyakarta 55253. In addition, it was also conducted partly in the Laboratory of Engineering Materials, Department of Mechanical and Industrial Engineering, Faculty of Engineering, Universitas Gadjah Mada.

\section{B. Specimen Preparation}

The material used for the welding process is low carbon steel, cut to a length of $200 \mathrm{~mm}$ and a width of $20 \mathrm{~mm}$ with a thickness of $2.9 \mathrm{~mm}$ according to the ASTM E8 standard [8].

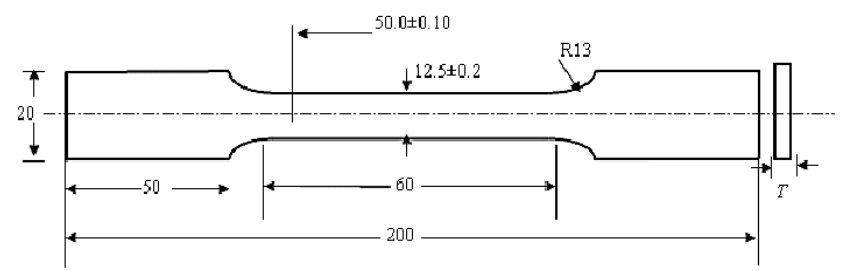

Figure 2. Specimen for Tensile Test [8]

The welding position used is a horizontal position or welding position under the hand. The welding stage is carried out in accordance with the cooling variable, the welding results that have been carried out will be cooled by using oil with a thickness of SAE $10 \mathrm{~W}-40$, fresh water, and room temperature. Metal chemical composition testing is used to determine the element content contained in the base metal. Metal composition testing is carried out with a spectrometer machine in the Laboratory of Engineering Materials, Universitas Gadjah Mada.

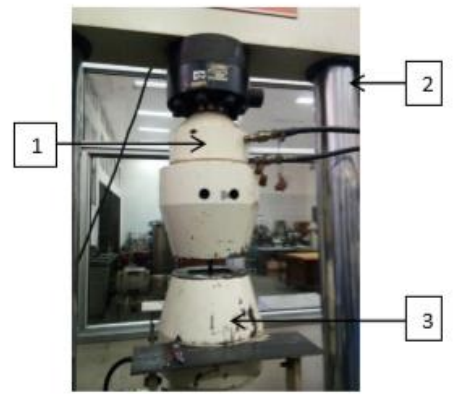

(a)

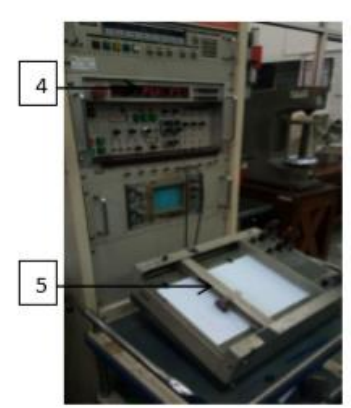

(b)
Figure 3. (a) Tensile Machine; (b) Scale reader and Plotter table

Caption : 1 = vise upper clamp; $2=$ hydraulic receipt; $3=$ vise down clamp; $4=$ Scale reader; $5=$ Plotter table

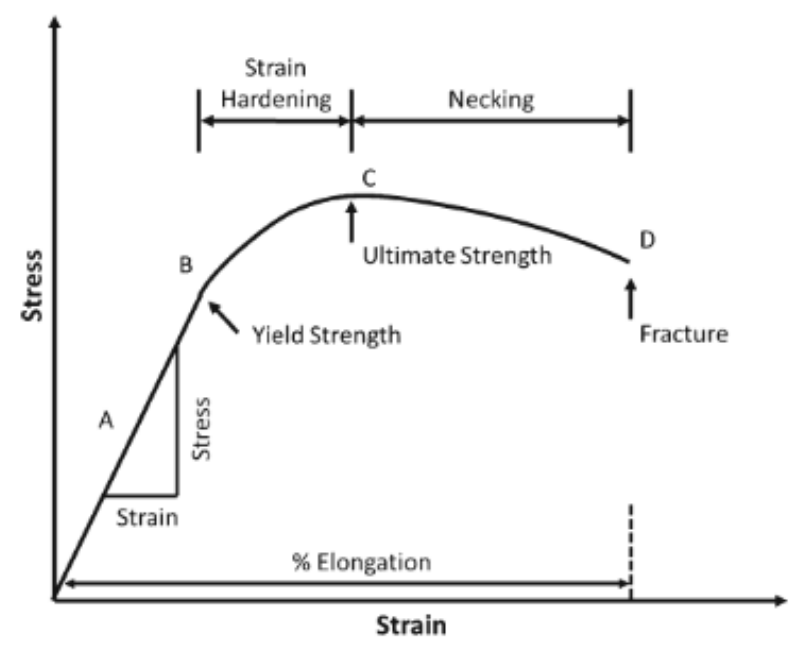

Figure 4. Stress and Strain Curve [9] 
Chemical composition testing aims to determine the carbon content and other elements contained in low carbon steel while tensile testing is a test conducted to determine the tensile strength of the results of SMAW welding joints with some cooling variations. Proper selection of processing parameters and regulation of the form of the welding bead is significant due to the fact that perhaps the strength of the welding is influenced not only by the chemical properties of the base and filling components, but also by the form of the welding bead. [10]. The tensile strength of the weld joint from several welding cooling variables will be applied to portable electric hydraulic jack products.

\section{Result and Discussion}

The process of testing the chemical composition of the material is to get the results of how much the value of the constituent elements of materials for example from the main elements $\mathrm{Fe}, \mathrm{C}, \mathrm{Mn}, \mathrm{Si}, \mathrm{Ni}$

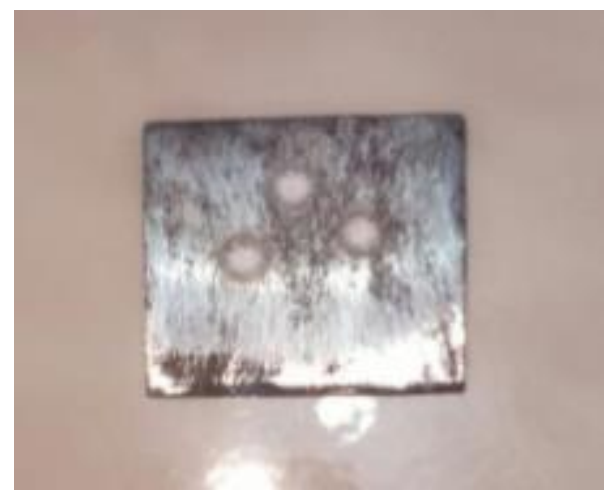

Figure 5. Chemical Composition Specimen

From the results of testing the chemical composition in this study can be seen in the table below:

Table 1. Chemical Composition

\begin{tabular}{|c|c|l|c|}
\hline No & Element & \multicolumn{1}{|c|}{ Information } & Value (\%) \\
\hline 1 & $\mathrm{Fe}$ & Ferro & 98.29 \\
\hline 2 & $\mathrm{C}$ & Carbon & 0.30 \\
\hline 3 & $\mathrm{Mn}$ & Manganese & 0.51 \\
\hline 4 & $\mathrm{Si}$ & Silicon & 0.23 \\
\hline 5 & $\mathrm{Ni}$ & Nickel & 0.04 \\
\hline 6 & $\mathrm{Cr}$ & Chromium & 0.37 \\
\hline
\end{tabular}

The results of testing the chemical composition of the ingredients in table 1 can be seen that the carbon content contained in the material is $0.30 \%$ and the content of Iron $(\mathrm{Fe})$ is $98.29 \%$ and there are other low guiding elements. In this case it can be concluded that this type of material is grouped from low carbon steel (low alloy steel).

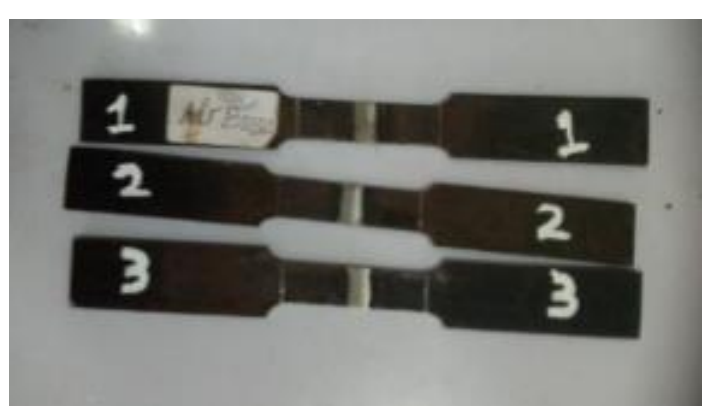

Figure 6. Tensile Test Specimen

In tensile testing using a servopulser machine with a maximum loading of $4,000 \mathrm{~kg}$ at room temperature. The test specimen consists of tensile testing and obtaining the tensile quality or force received on the low carbon steel from the SMAW welding results using E6013 electrodes and welding electric current $75 \mathrm{~A}$. In the present study, three welding processes, including polarity, electrodes angles and work piece, were taken into account to measure the tensile strength of the welded joint. Prediction of tensile strength is important to address the difficulties related with welded joints under various welding conditions [5].

Table 2. Tensile Strength Test Results on Low Carbon Steel

\begin{tabular}{|c|c|c|c|}
\hline $\begin{array}{c}\text { Cooling } \\
\text { Medium }\end{array}$ & $\boldsymbol{\sigma}(\mathbf{M P a})$ & $\mathbf{e}(\boldsymbol{\%})$ & $\mathbf{E}\left(\mathbf{N} / \mathbf{m m}^{\mathbf{2}}\right)$ \\
\hline Water & 739.2 & 2.4 & 308 \\
\hline Oil & 844.76 & 1.2 & 703.9 \\
\hline $\begin{array}{c}\text { Room } \\
\text { temperature }\end{array}$ & 744.4 & 16 & 46.525 \\
\hline
\end{tabular}

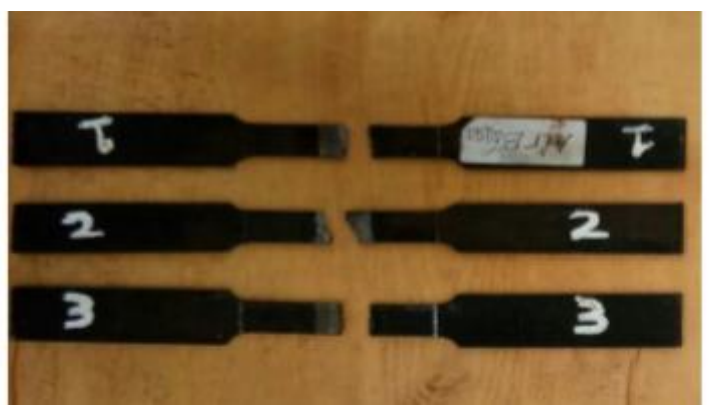

Figure 7. Specimens after Tensile Testing

The magnitude of the change in plastic deformation in room temperature media has an elongation value (e) of $1.2 \%$, at which point the test material undergoes structural changes. The tensile strength value on low carbon steel has an average value of $844.76 \mathrm{MPa}$, this states that the strength of a material is indicated by the slope of the line on the stress-strain 
curve in the elastic region before reaching the breaking point.

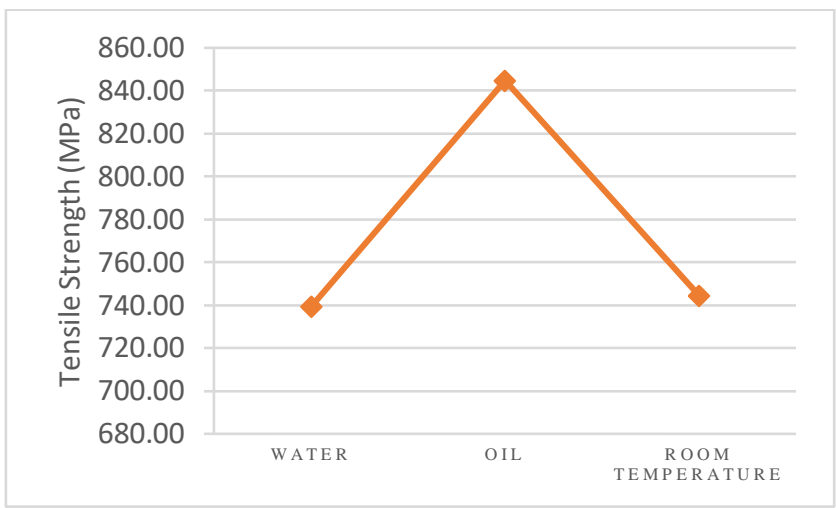

Figure 8. Chart of Tensile Strength

Oil is a very slow cooling medium. Oil also has the highest viscosity or viscosity value compared to other cooling media and low density so that the cooling rate is slow so that it can give a very high influence on the strength of the material in welding [11].

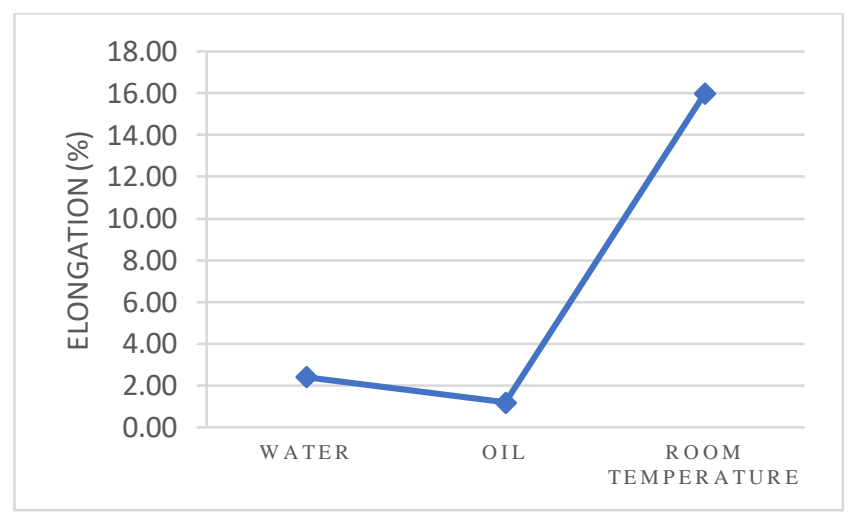

Figure 9. Chart for Elongation in Tensile Test (e)

The highest value of elongation of cross section reduction (strain) is obtained on the cooling medium of room temperature compared to the cooling treatment using water and oil.

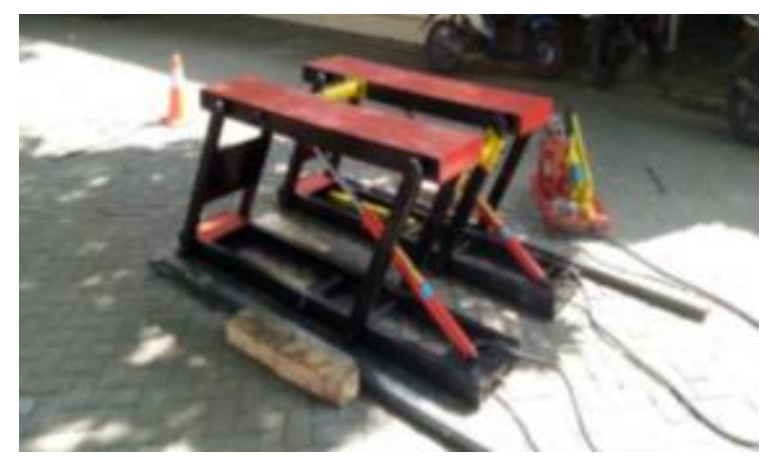

Figure 10. Portable Electric Hydraulic Jack Frame
The results obtained in research on the analysis of the mechanical properties of the weld joint above were applied to the manufacture of Portable Electric Hydraulic Jack Frames for car hanging (Figure 10).

\section{Conclusion}

1. The cooling media by using oil is a good cooling medium. The use of used oil as a cooling medium will cause the formation of carbon coatings on specimens depending on the amount of viscosity, so that it can give a very high influence on the strength of the material in welding. Tensile stress and elasticity values obtained with oil cooling media is 844.76 $\mathrm{MPa}$ and $\mathrm{E}$ value is $703.96 \mathrm{~N} / \mathrm{mm}^{2}$

2. The value of low carbon steel elongation with oil cooling media in this study was $1.2 \%$. Provision of cooling media after welding can improve the tensile strength properties of the welding results.

3. For further work, if the SMAW welding process on material thickness of more than $2.90 \mathrm{~mm}$ using E6013 electrodes with electrode diameters of 2.6 $\mathrm{mm}$ should use a current of 100 to 130 , because if using a small current results in penetration of the parent metal is less melting.

\section{References}

[1] S. K. Weerasekaralage, "Optimization of Shielded Metal Arc Welding (SMAW) Process for Mild Steel." [Online]. Available:

https://www.researchgate.net/publication/335174446_Optimi zation of Shielded Metal Arc Welding SMAW process $\mathrm{f}$ or_mild_steel

[2] H. Wiryosumarto, 1996, Metal Welding Technology. Jakarta: Pradnya Paramita.

[3] S. Pujo M. Imam, 2008. "Analysis of Las Smaw (Shielded Metal Arc Welding) Connection Strength on Marine Plate St 42 Due to Porosity and Incomplete Penetration Defects", ejournal Universitas Diponegoro, Vol. 5, No. 2.

[4] I. Alkahla and S. Pervaiz, 2017, "Sustainability Assessment Of Shielded Metal Arc Welding (Smaw) Process", IOP Conference Series: Materials Science and Engineering, Vol. 244.

[5] D. Pathak, et al., 2020, "Experimental investigation of effects of welding current and electrode angle on tensile strength of shielded metal arc welded low carbon steel plates," Materials Today: Proceedings, Vol. 26, Part 2, pp. 929-931.

[6] A. I. Dicky Adi Tyagita, 2016, "Tensile Strength Welding Results Smaw St 37 Steel Plate With Liquid Coolant", Ilmiah Inovasi, Vol. 1. No.3. Politeknik Negeri Jember, pp. 180-186, 2016.

[7] S. Faidillah, et al. 2019, "Effect of AHM Radiant Coolant (RC) Cooling on Tensile Strength of SMAW Welding Results on ST 37 Steel Plate", Repository Universitas Muhammadiyah Jember, July, 92019. 
[8] Standard Test Methods for Tension Testing of Metallic Materials 1, 2013. United States of Amerika, E8/E8M-13a, 2013.

[9] H. Lim and S. W. Hoag, 2013, "Plasticizer effects on physicalmechanical properties of solvent cast Soluplus ${ }^{\circledR}$ films", (in eng), AAPS PharmSciTech, Vol. 14, No. 3, pp. 903-10, Sep 2013.

[10] L. P. Connor and R. O'Brien, 1991, Welding handbook: welding processes. Amer Welding Society, 1991.

[11] N. F. Sultoni, M. Agus Sahbana, 2019, "Analysis of the Effect of Water and Oil Cooling Media Variations on Lap Joint Connections on Mechanical Properties Using SMAW (DC)," Proton, Vol. 11, No.1, Universitas Widyagama Malang, pp. $35-42$. 